DD

$$
\text { sw } 9404
$$

KEK Preprint 93-118

OULNS 92-07

September 1993

H

\title{
Electron Identification with upgraded VENUS Detector
}

A. KRÜGER, J. HABA, N. KANDA, Y. NAGASHIMA, D. TATSUMI,
K. OGAWA, M. SAKUDA and T. SUMIYOSHI

Submitted to Nucl. Instrum. Meth. 
National Laboratory for High Energy Physics, 1993

KEK Reports are available from:

Technical Information \& Library

National Laboratory for High Energy Physics

1-1 Oho, Tsukuba-shi

Ibaraki-ken, 305

JAPAN

Phone: $\quad 0298-64-1171$

Telex: 3652-534 (Domestic)

(0)3652-534 (International)

Fax: $\quad$ 0298-64-4604

Cable: $\quad$ KEK OHO

E-mail: LIBRARY@JPNKEKVX (Bitnet Address)

library@kekvax.kek.jp (Internet Address) 


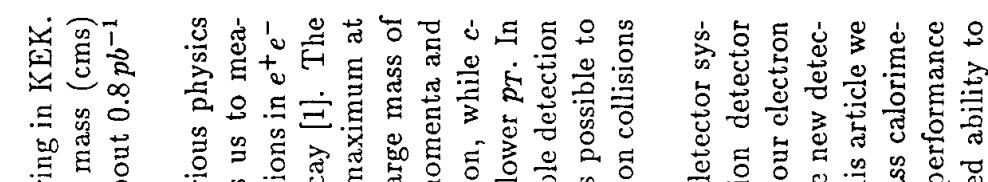

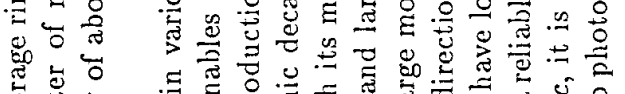

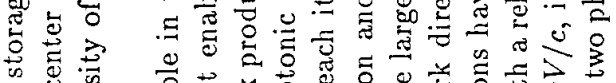

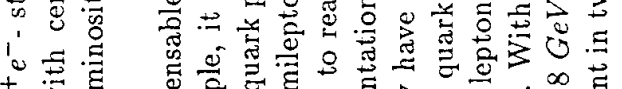

t高焉

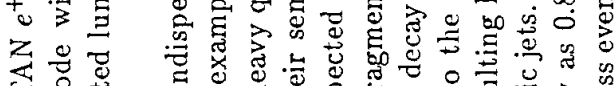

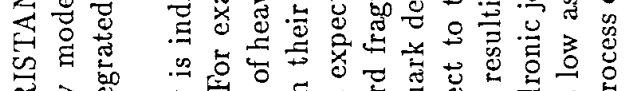

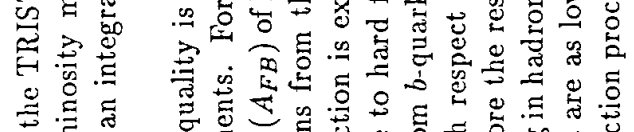

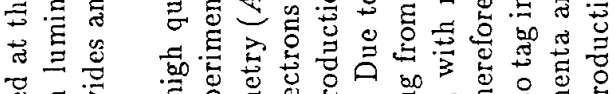

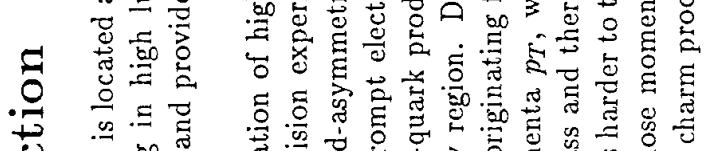

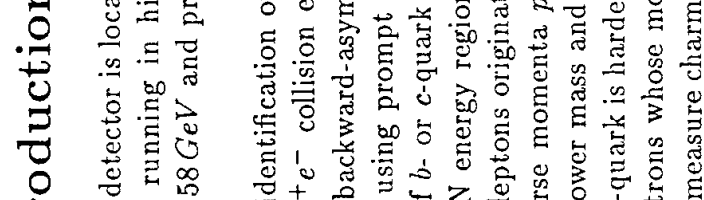

苟 n.

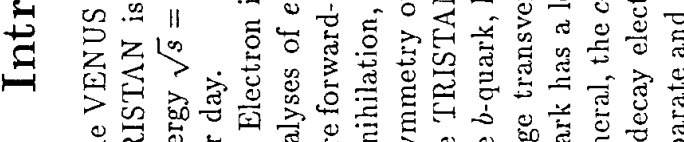

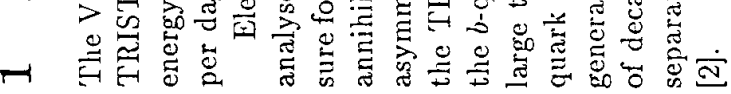

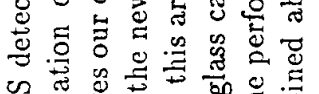

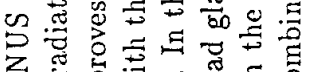

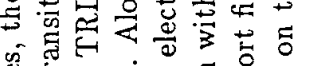

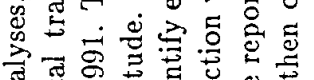

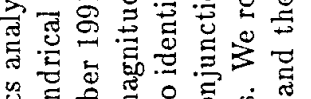

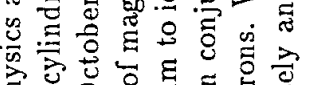

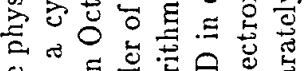

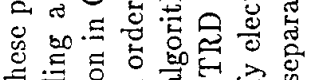

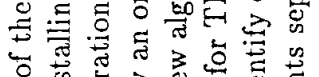

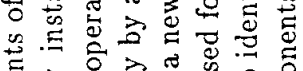

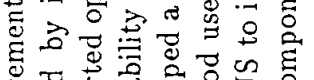

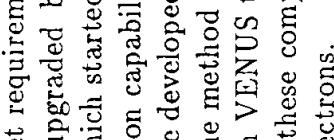

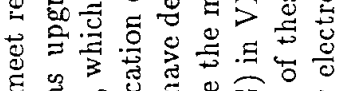

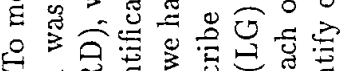

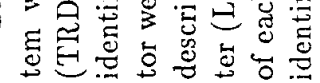

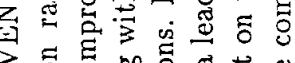

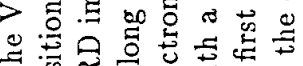

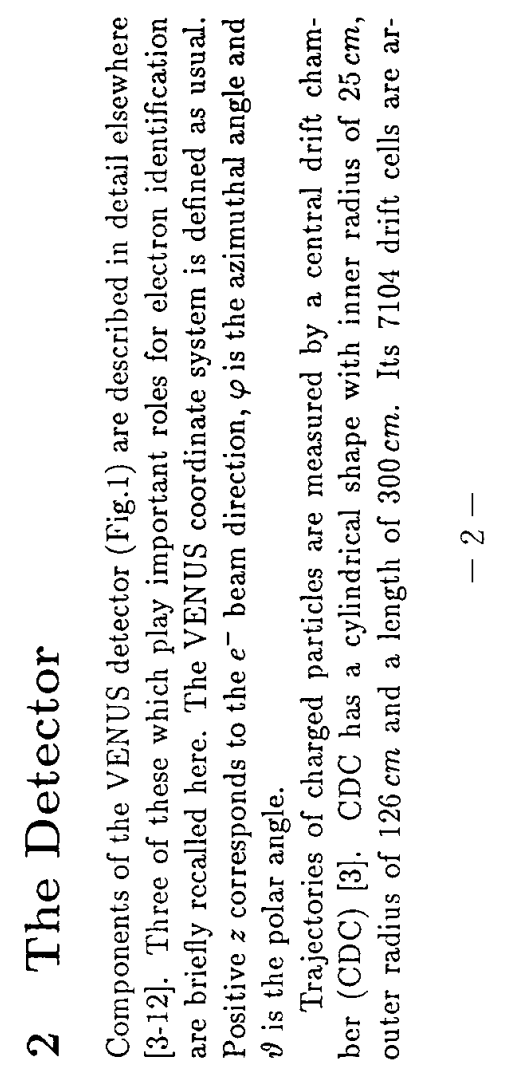

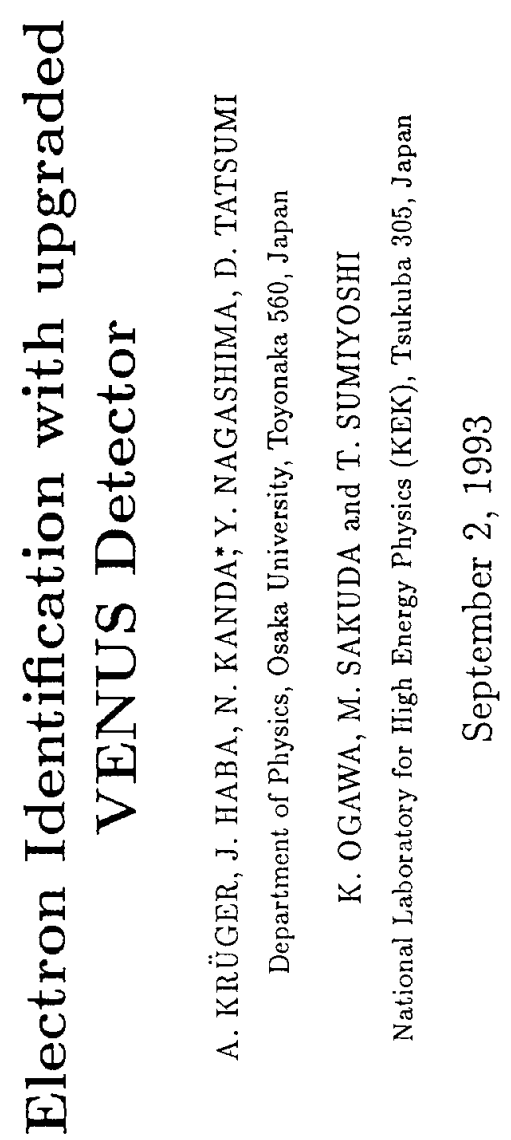

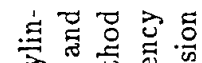

उ.

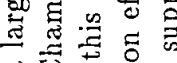

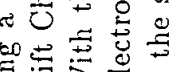

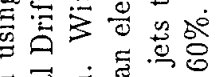

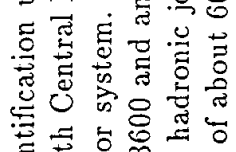

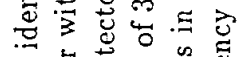

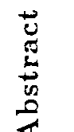

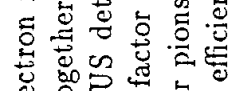

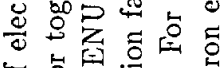

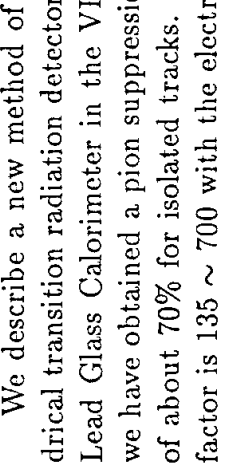

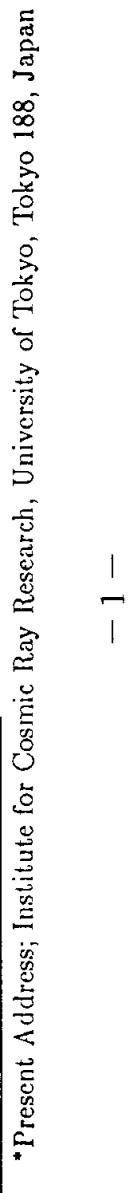




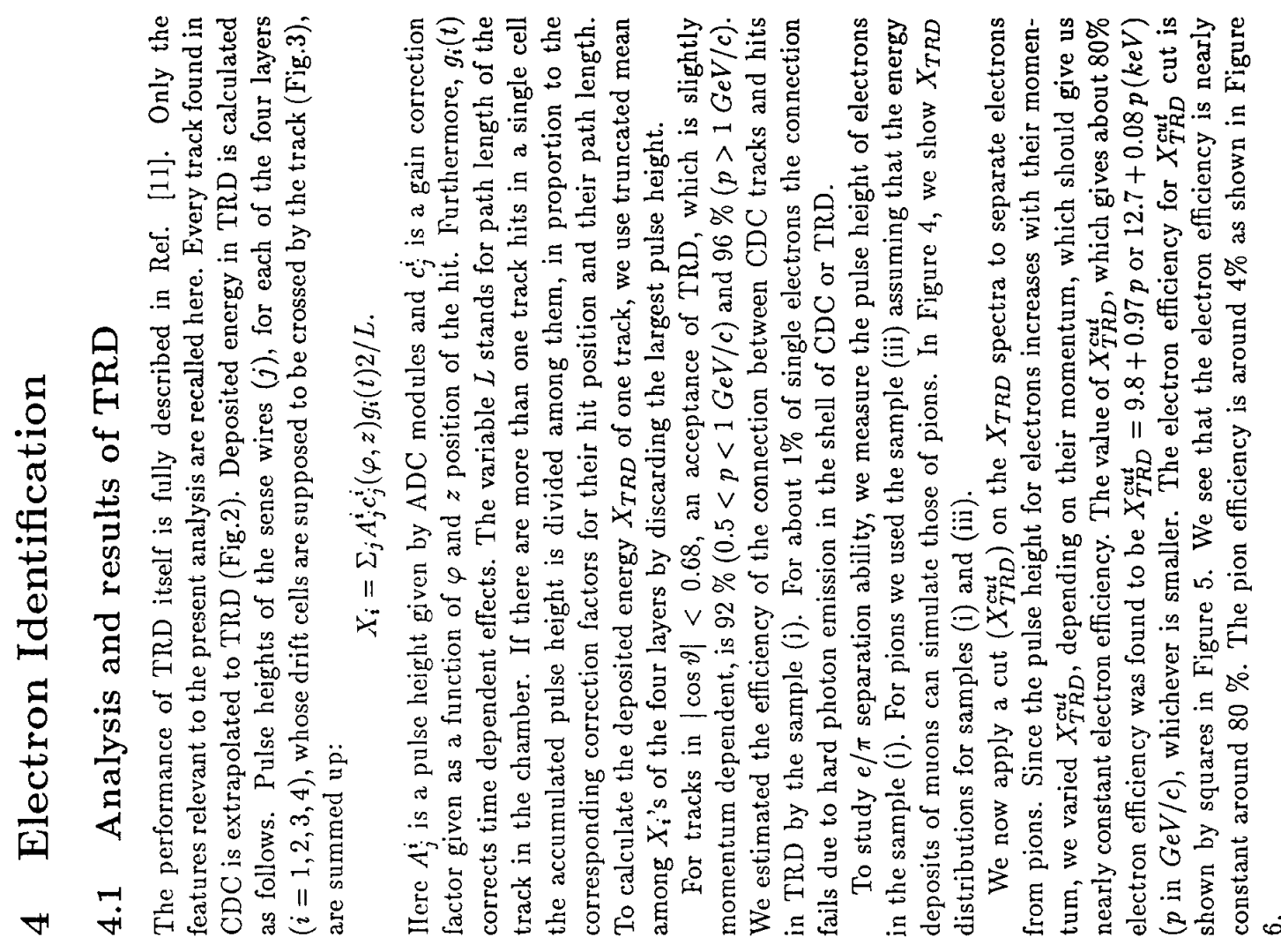

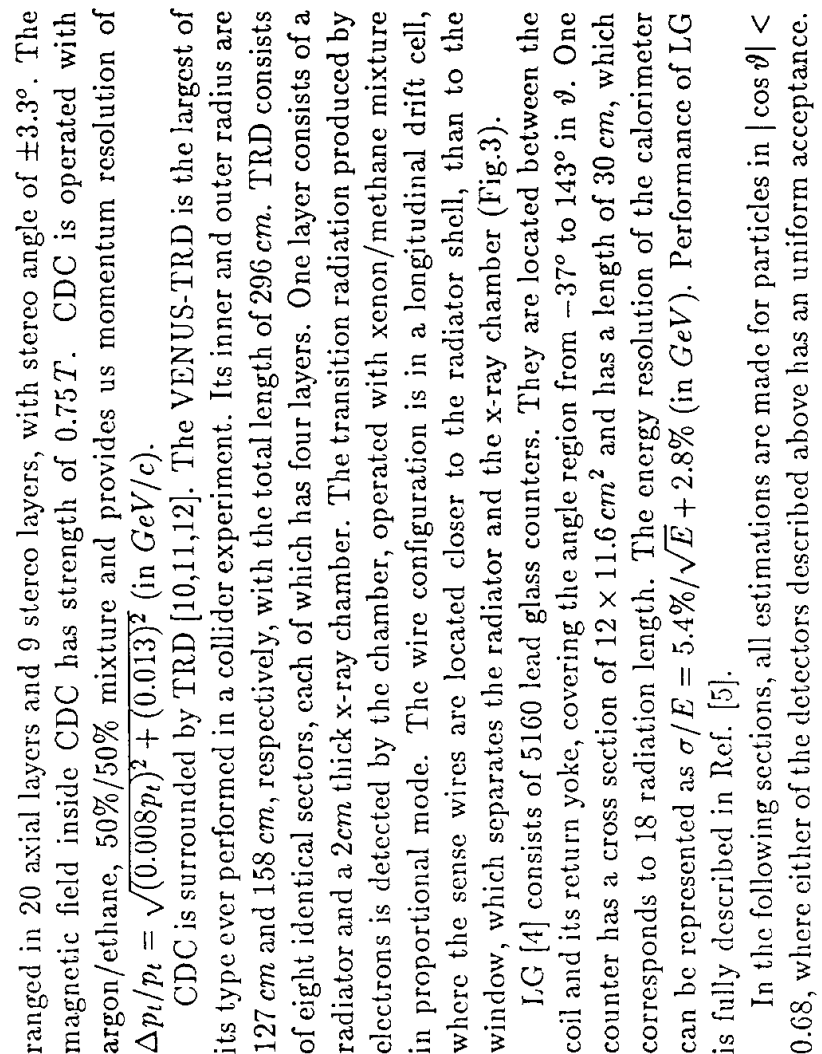

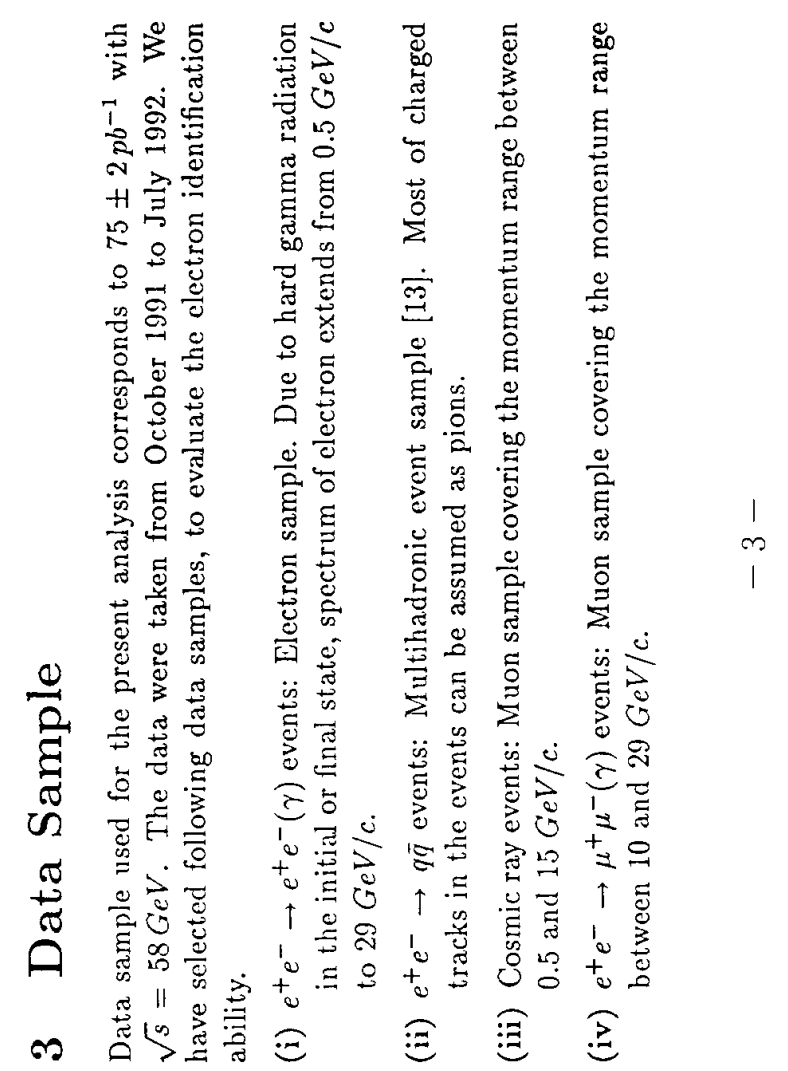



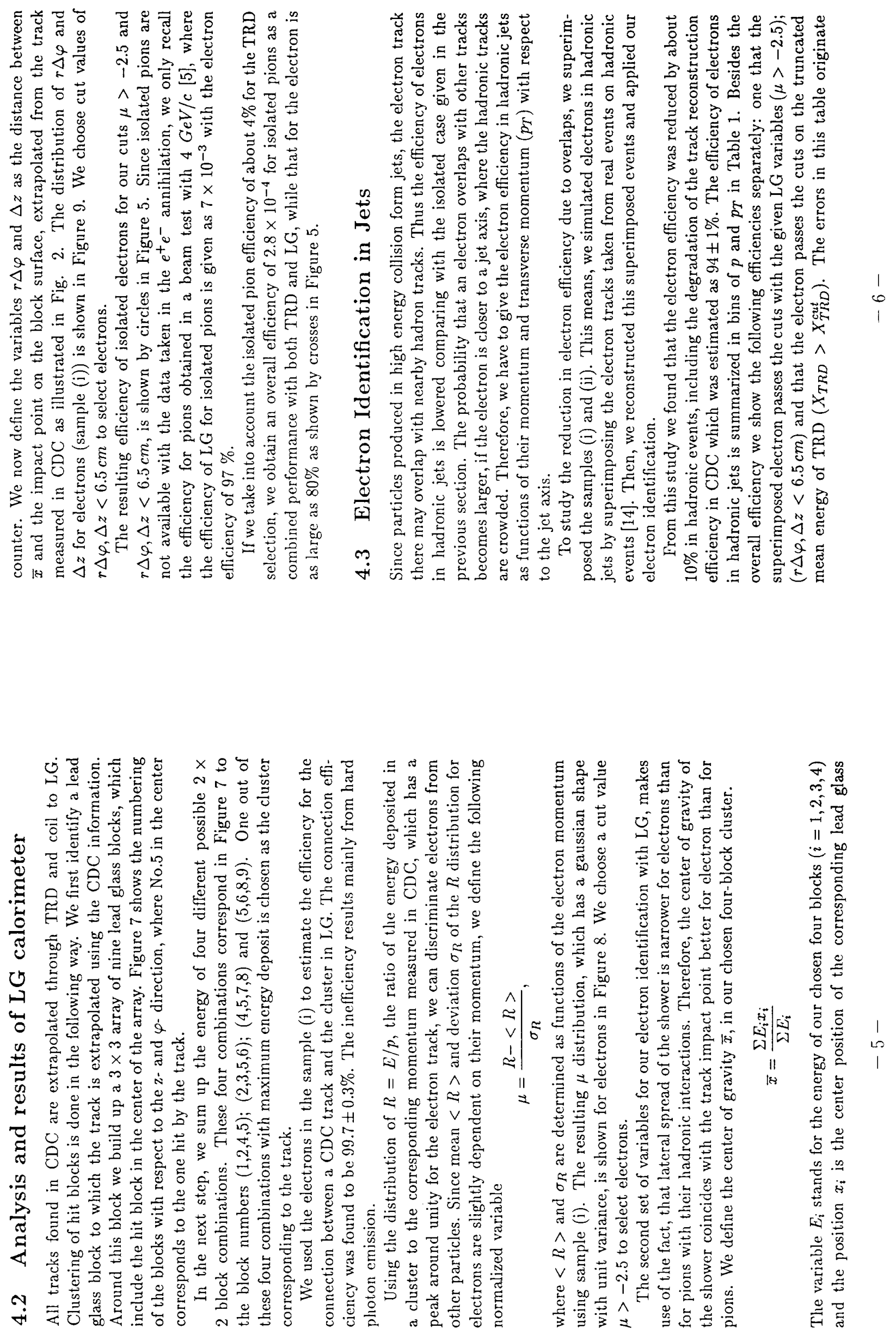

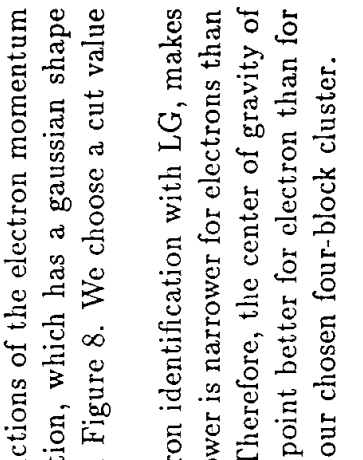

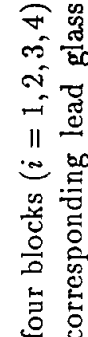

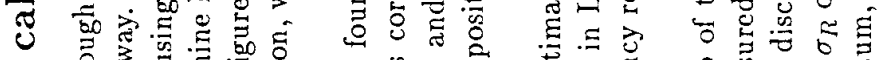

U

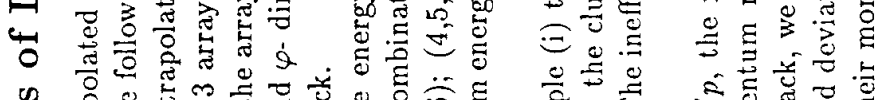

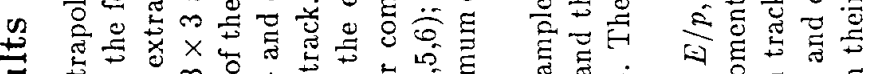

ت.

=

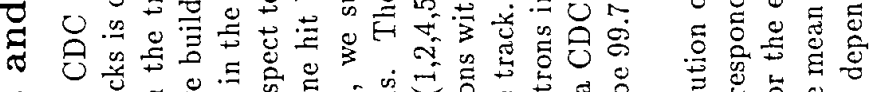

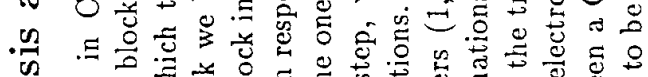

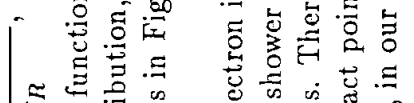

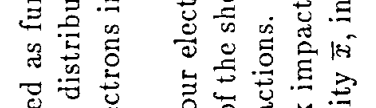

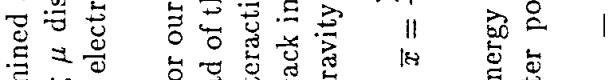

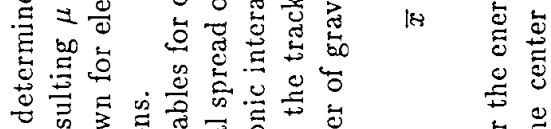

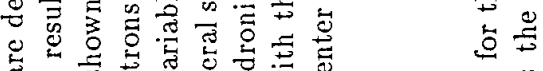

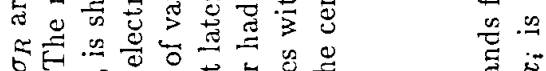

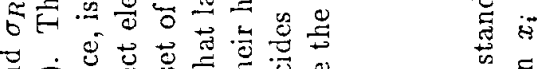

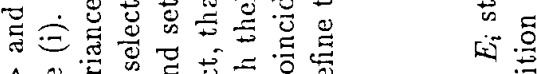

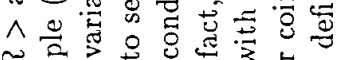

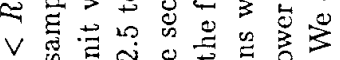

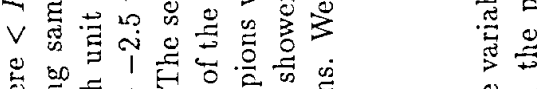

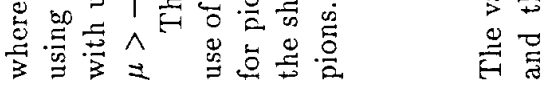




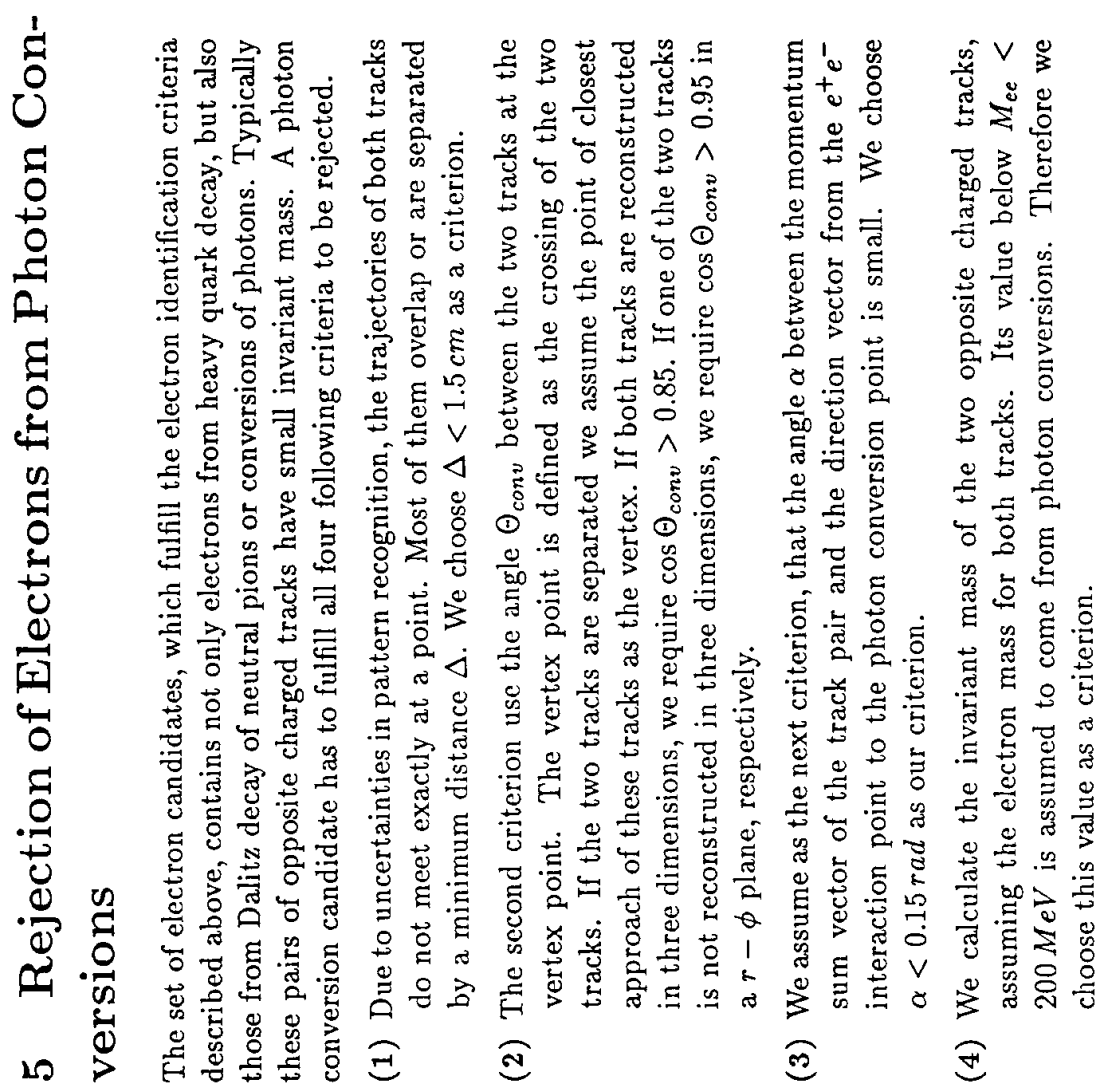

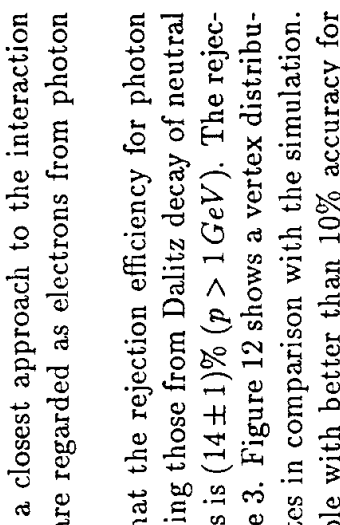

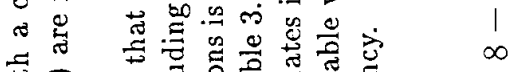

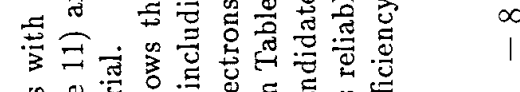

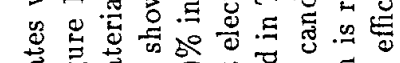

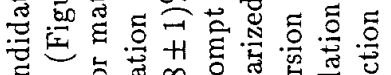

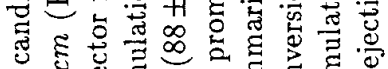

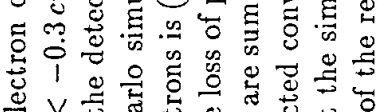

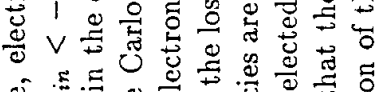

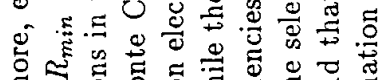

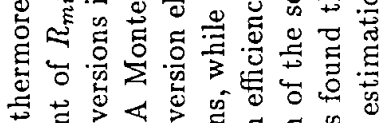

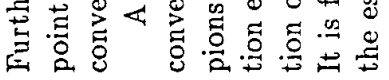

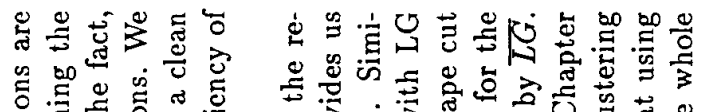

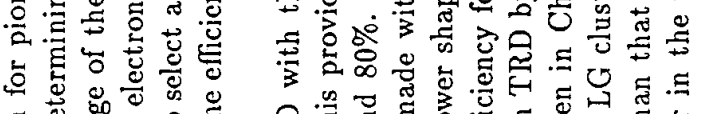

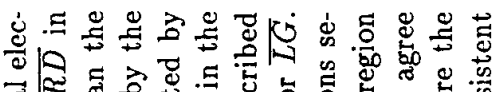

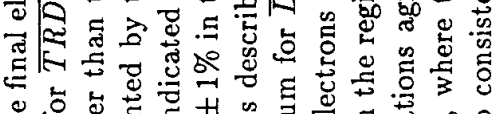

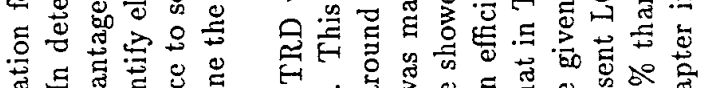

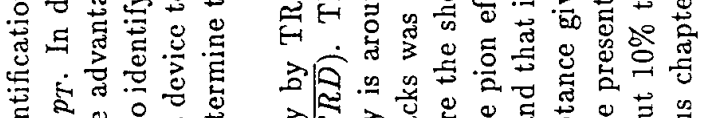

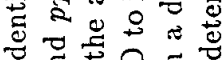

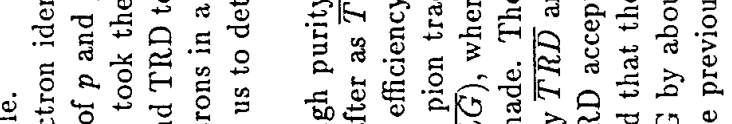

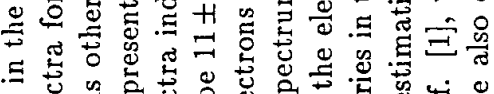
to

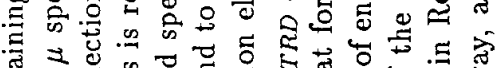

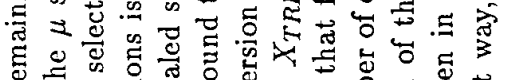

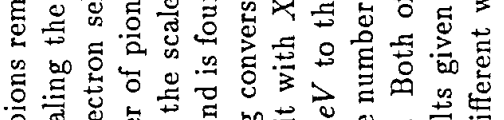

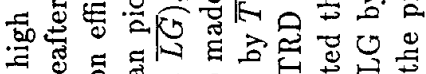

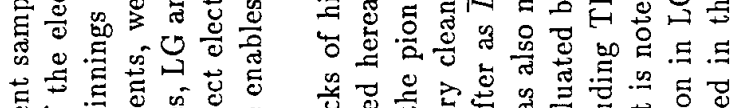

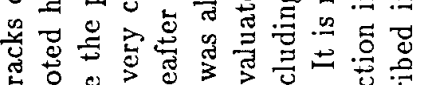

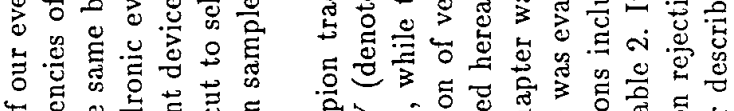

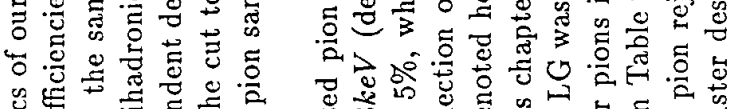

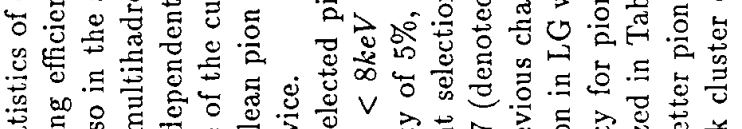

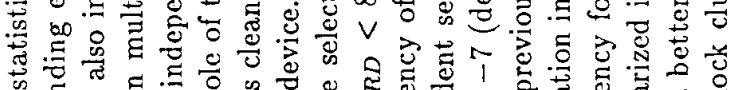

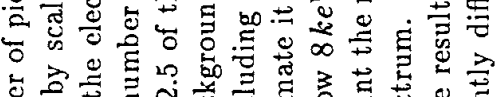

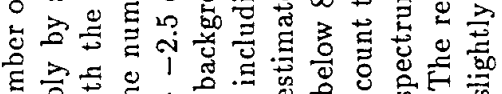

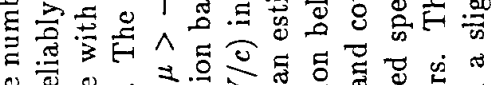

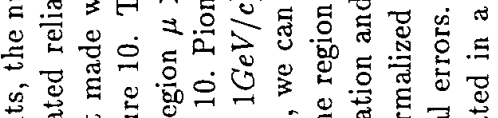

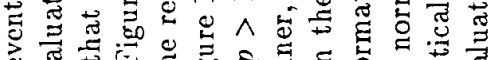

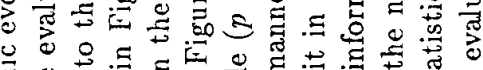

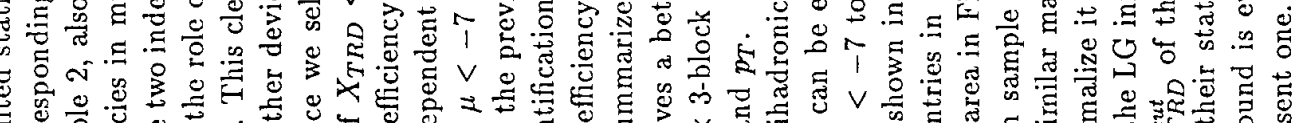

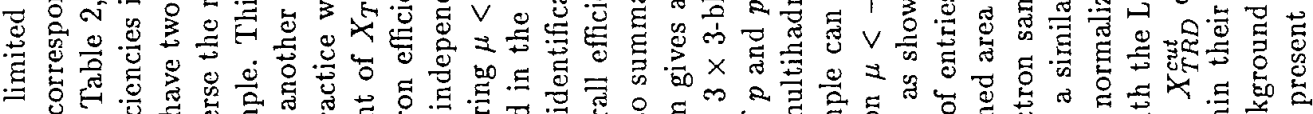

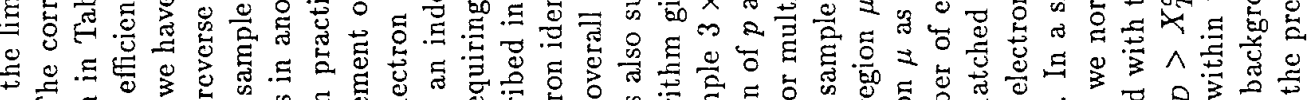

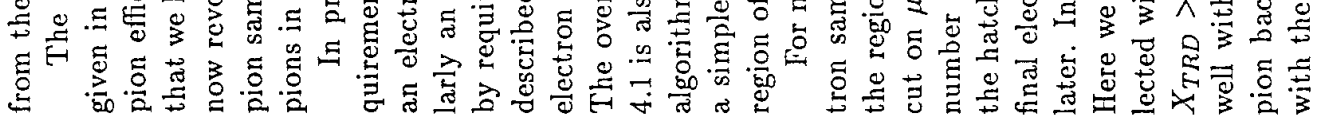



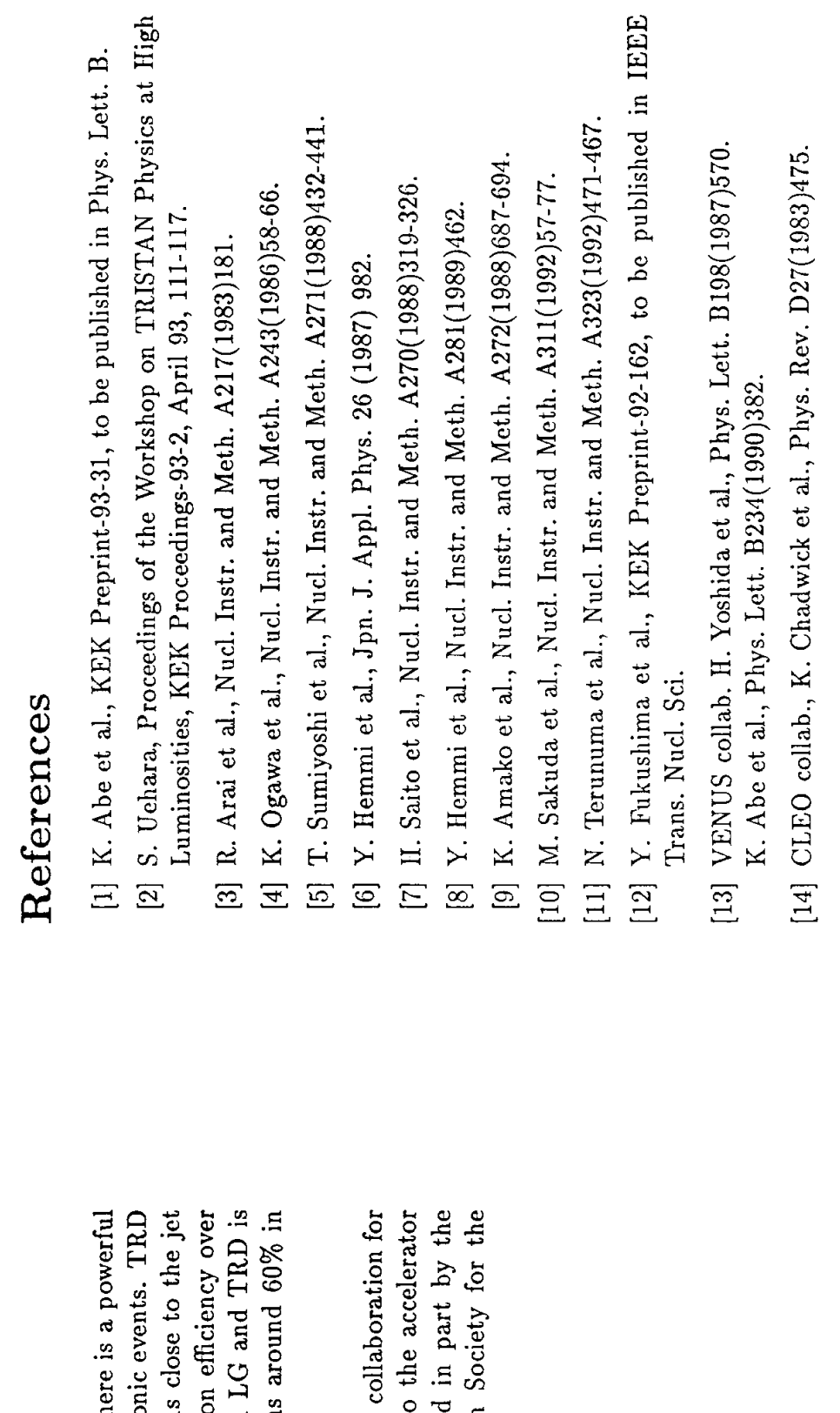

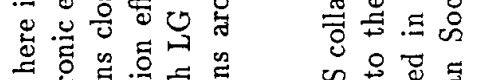

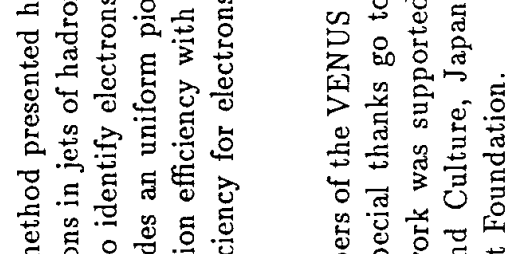

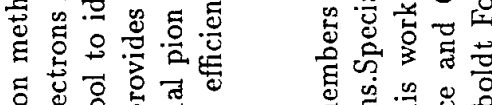

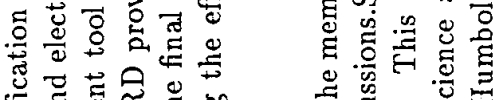

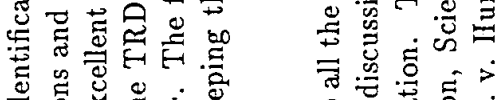

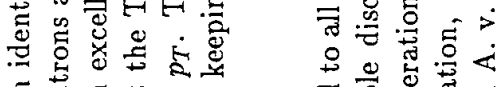

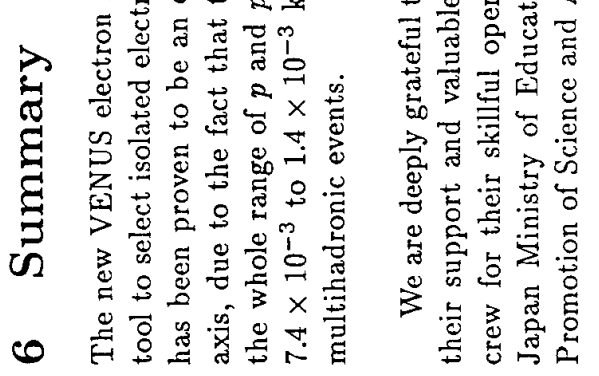



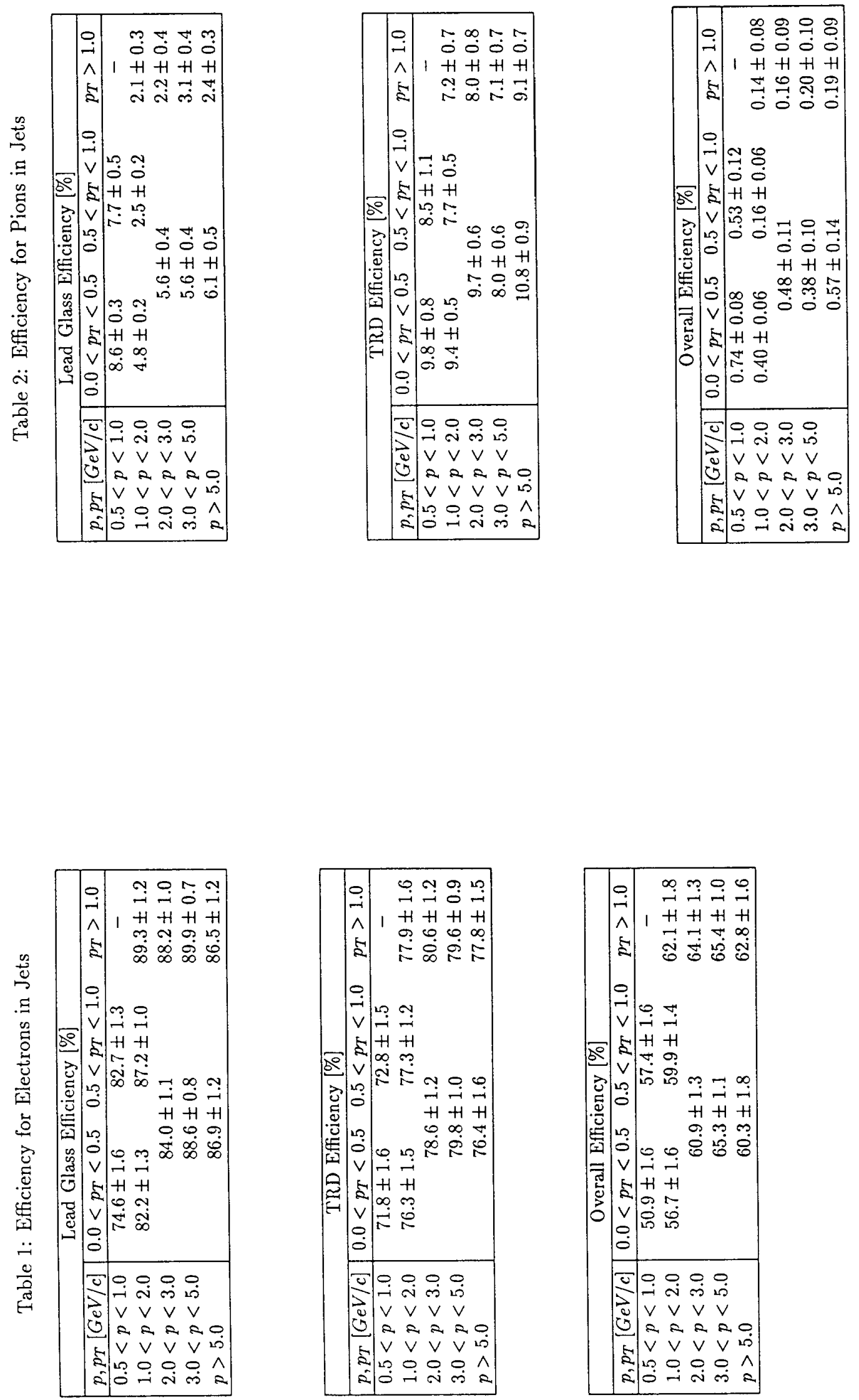

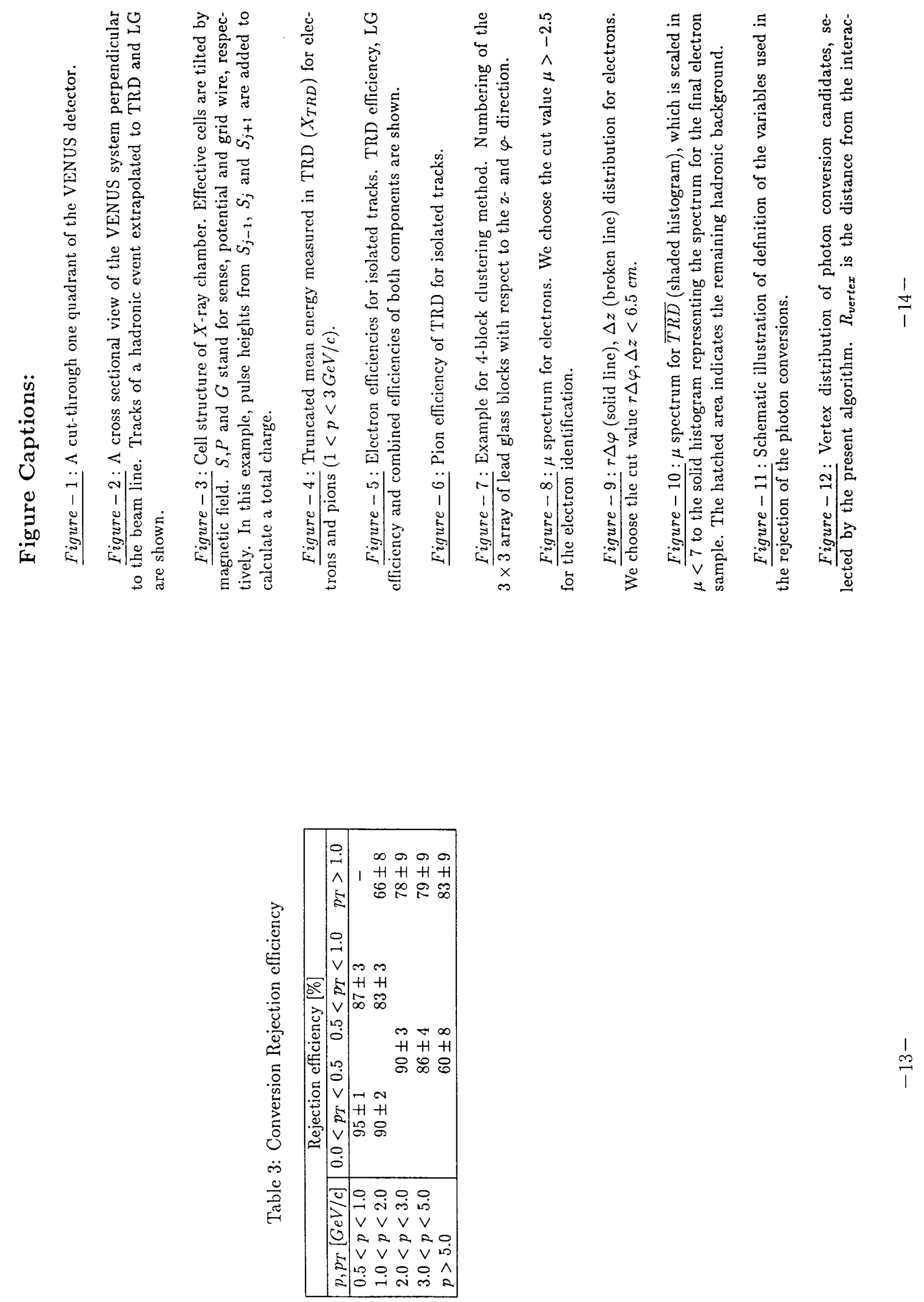
$\mid$ 


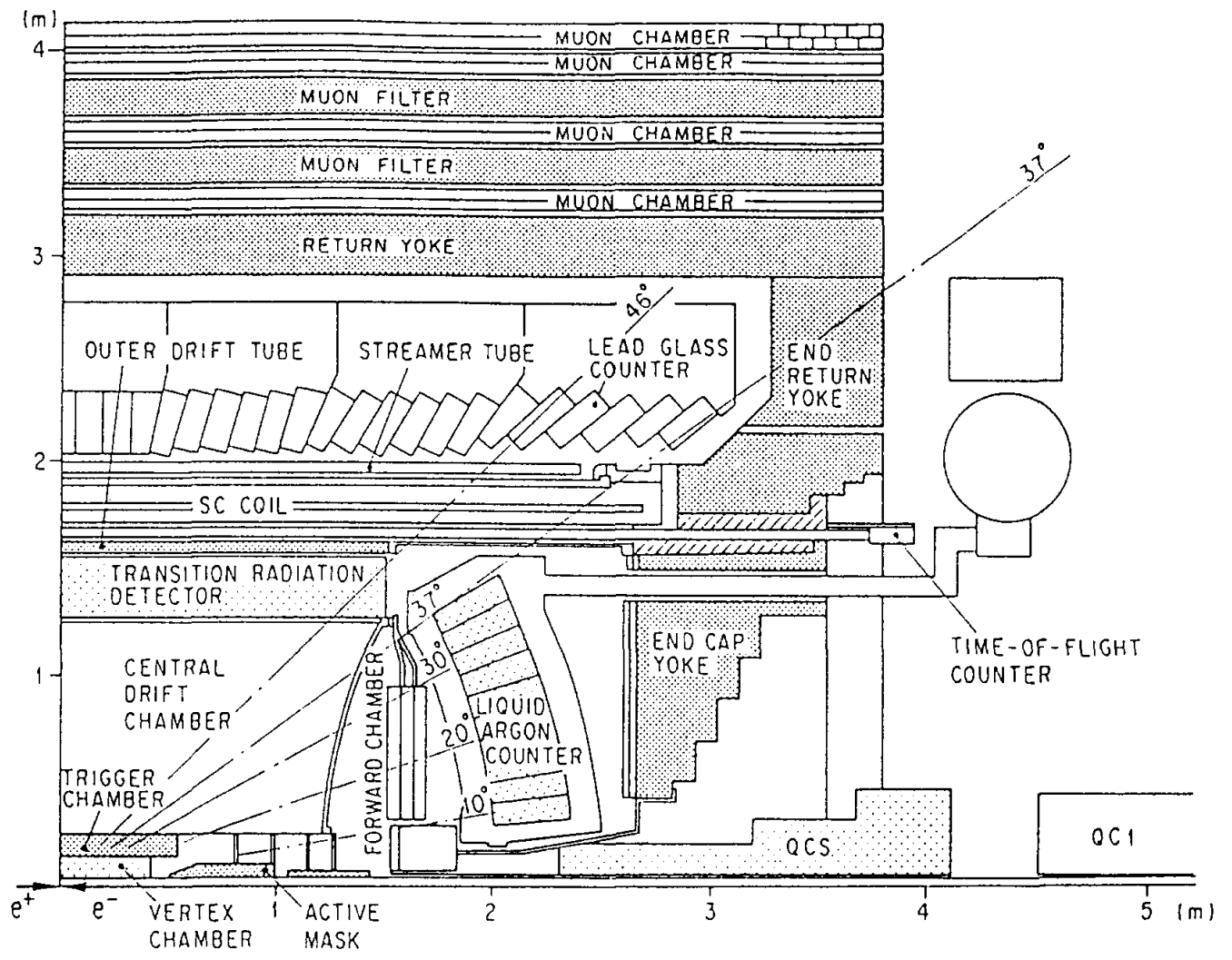

Fig. 1

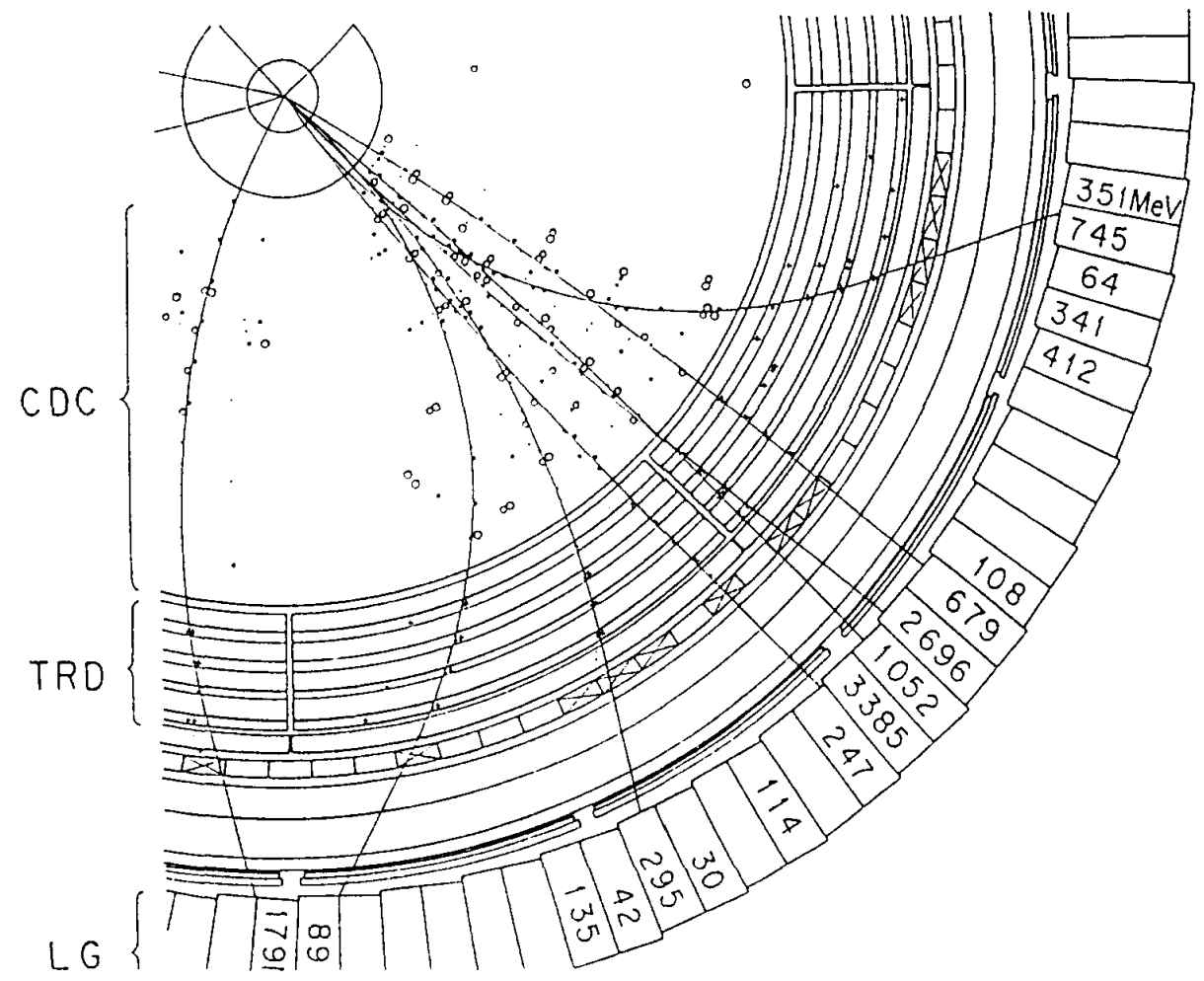

Fig. 2 


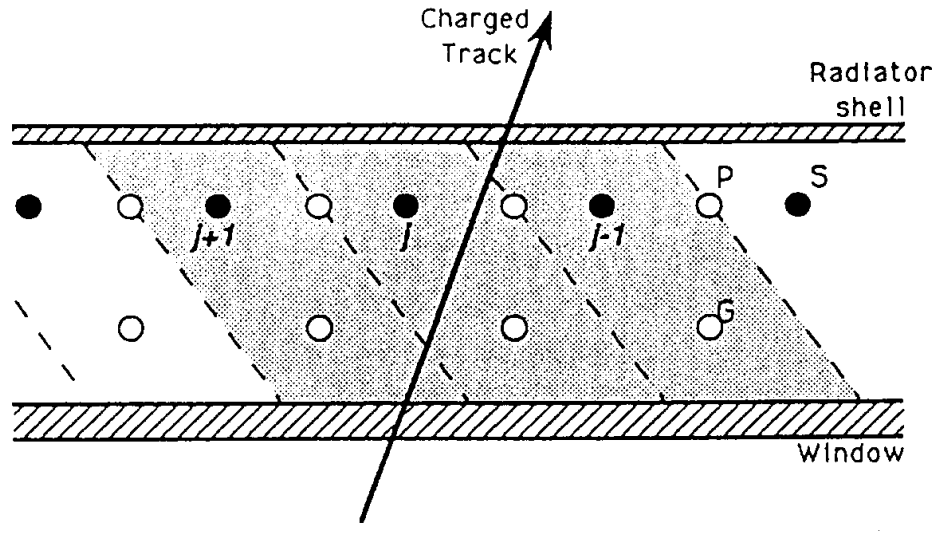

Fig. 3

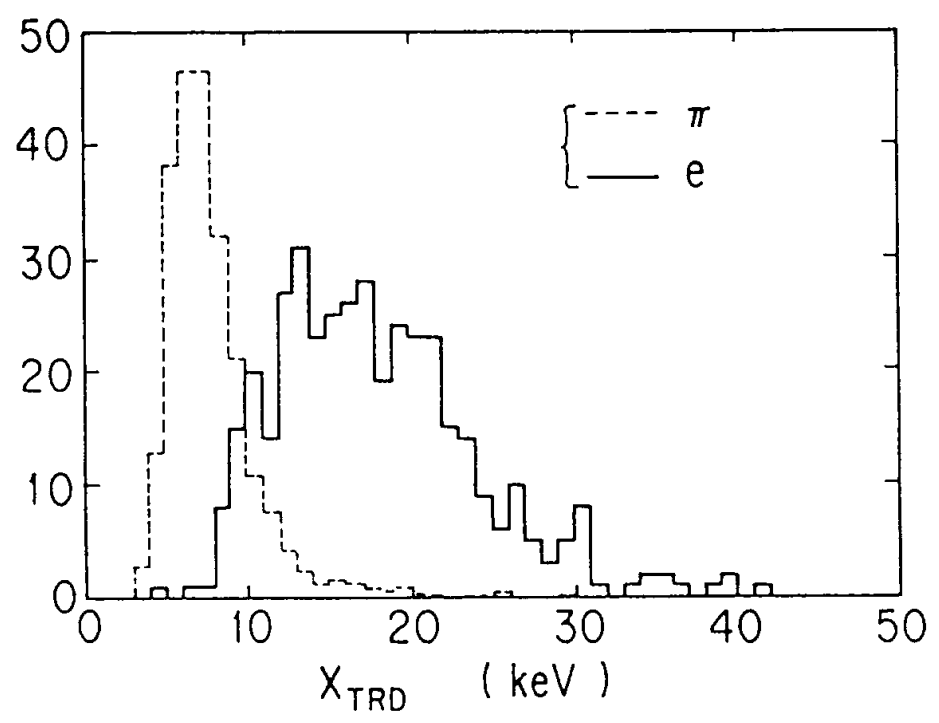

Fig. 4 


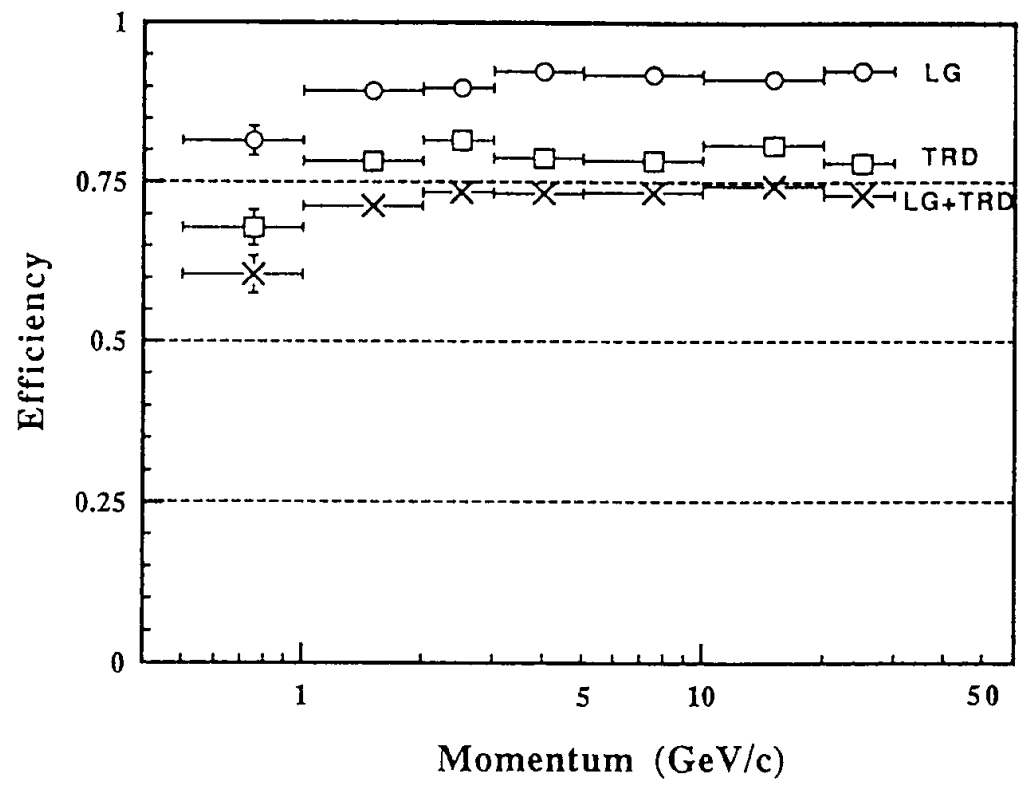

Fig. 5

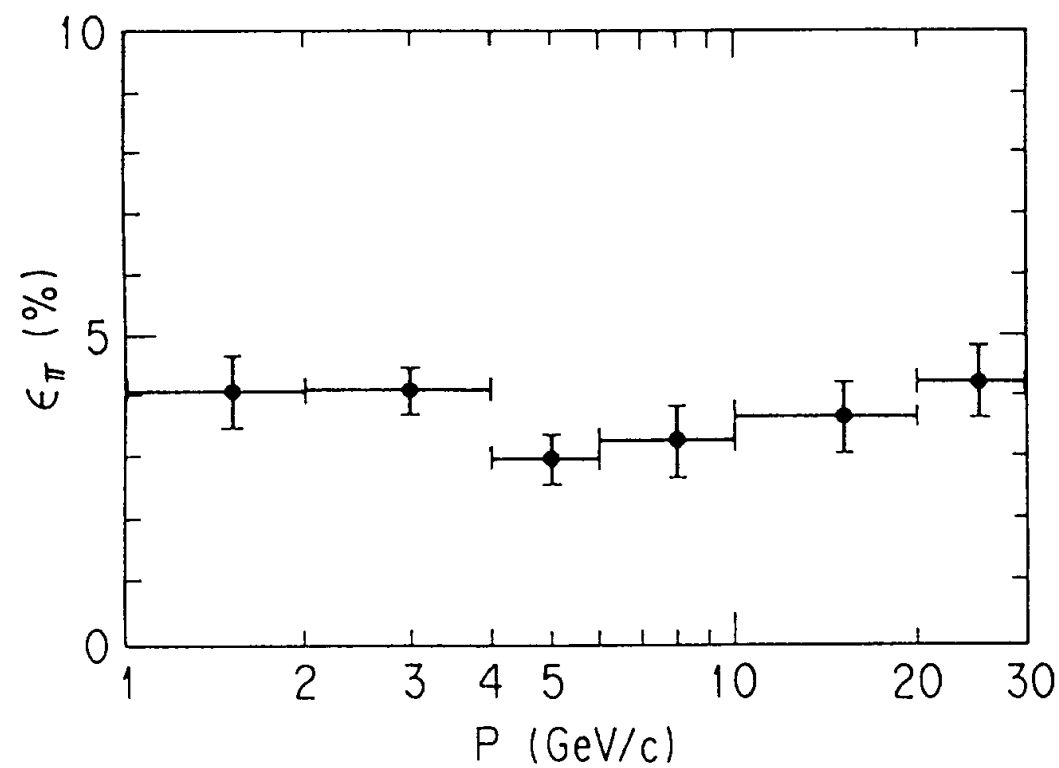

Fig. 6 


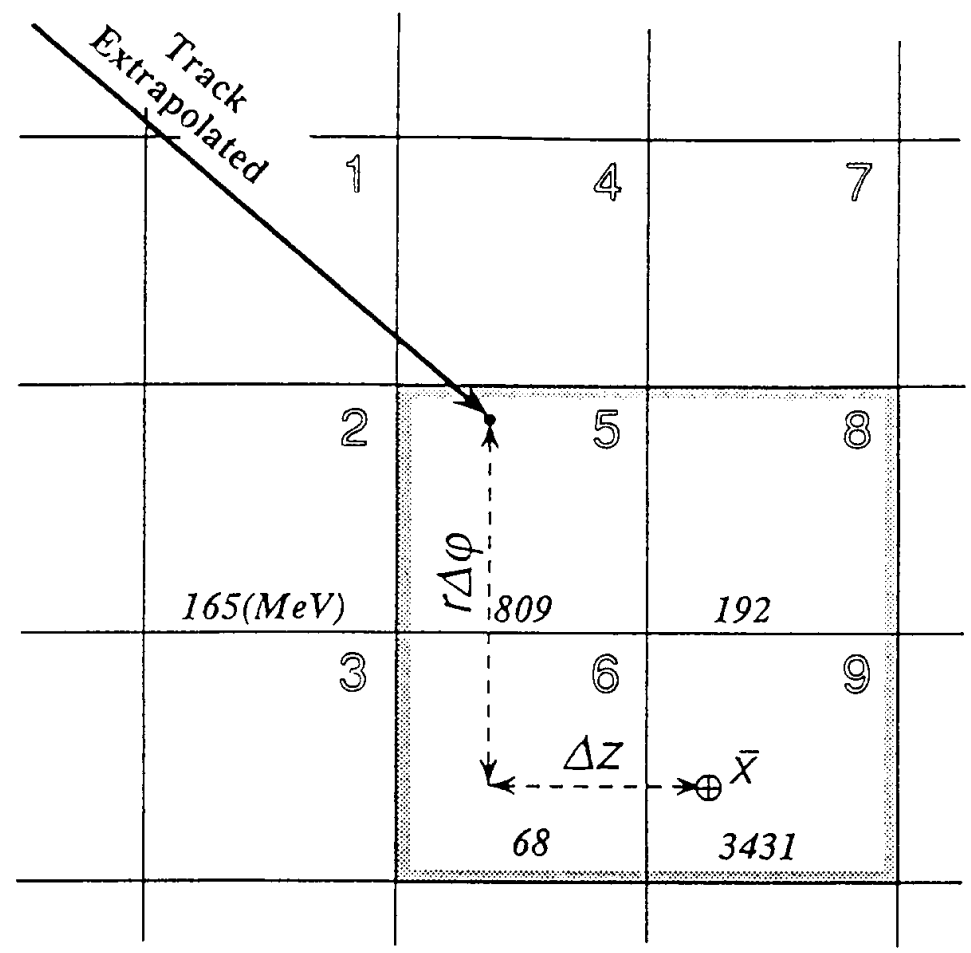

Fig. 7

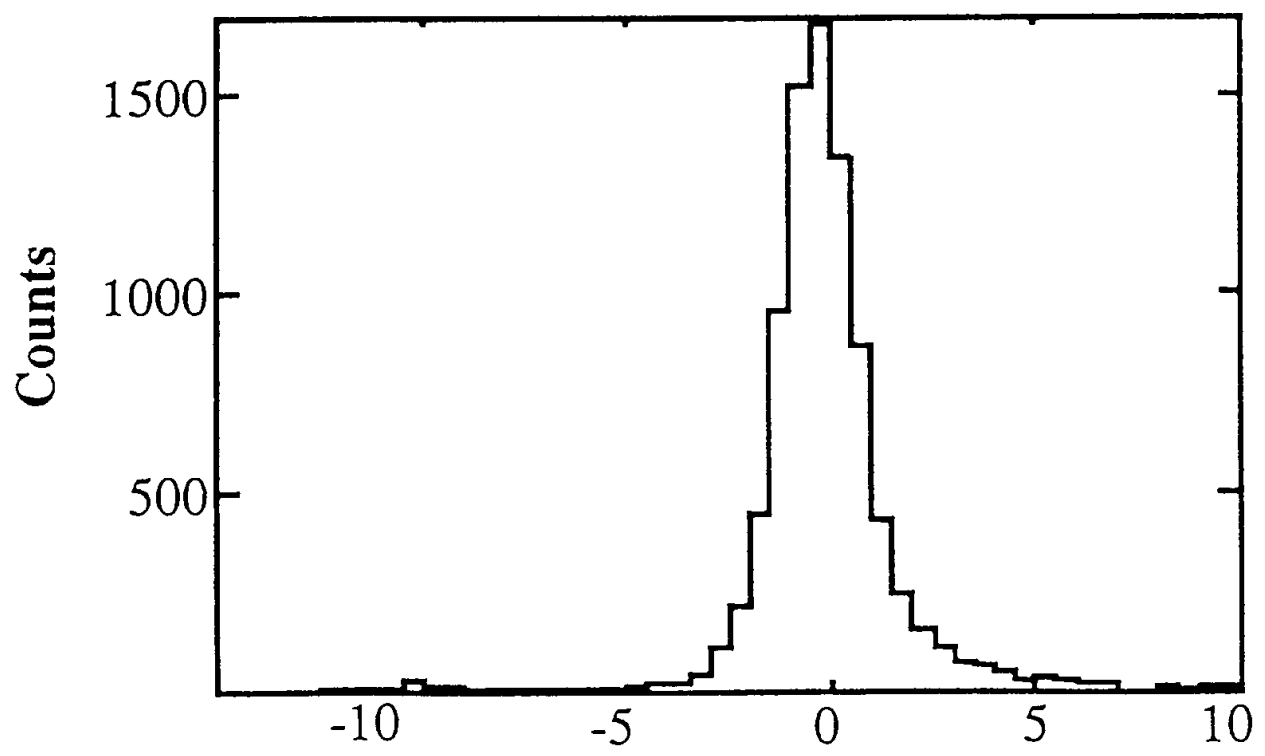

Fig. 8 


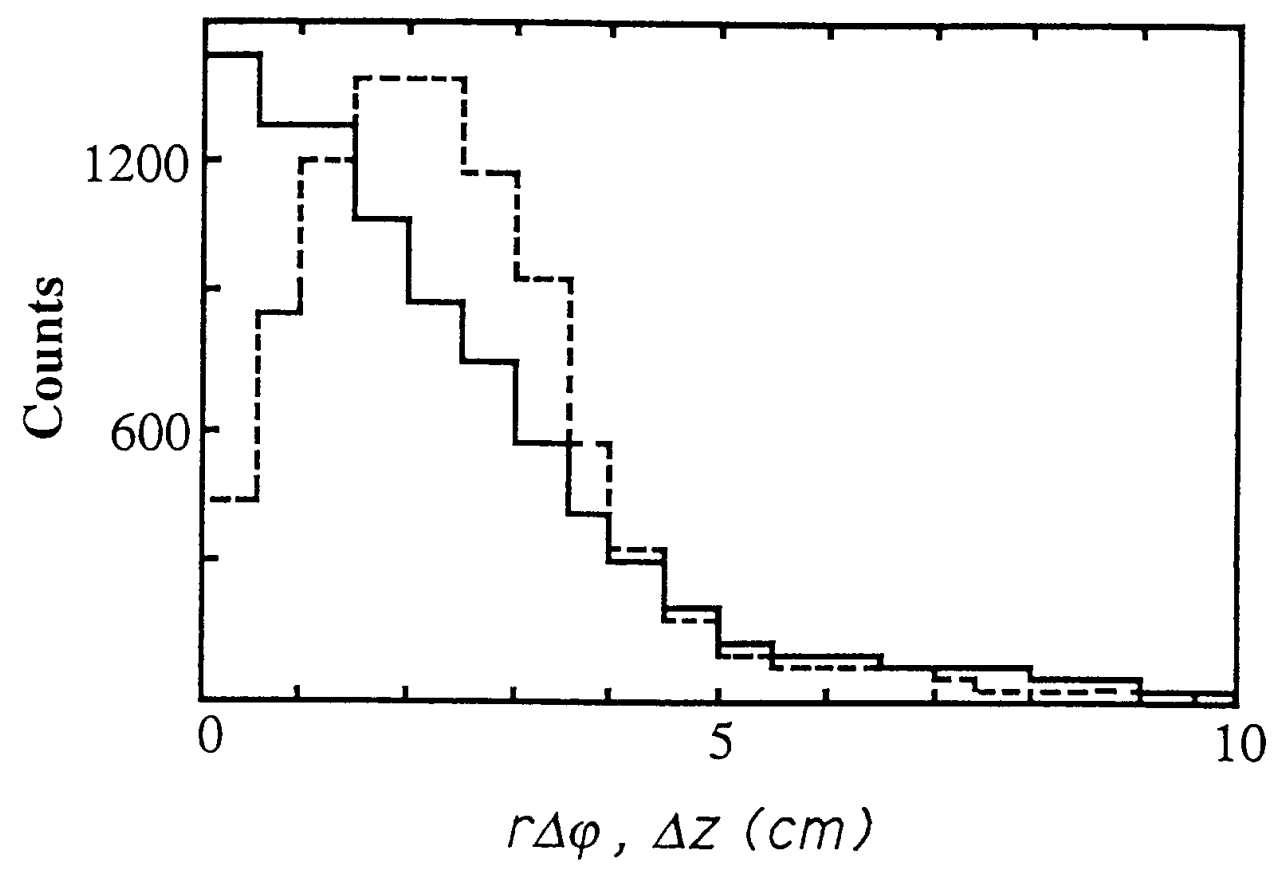

Fig. 9

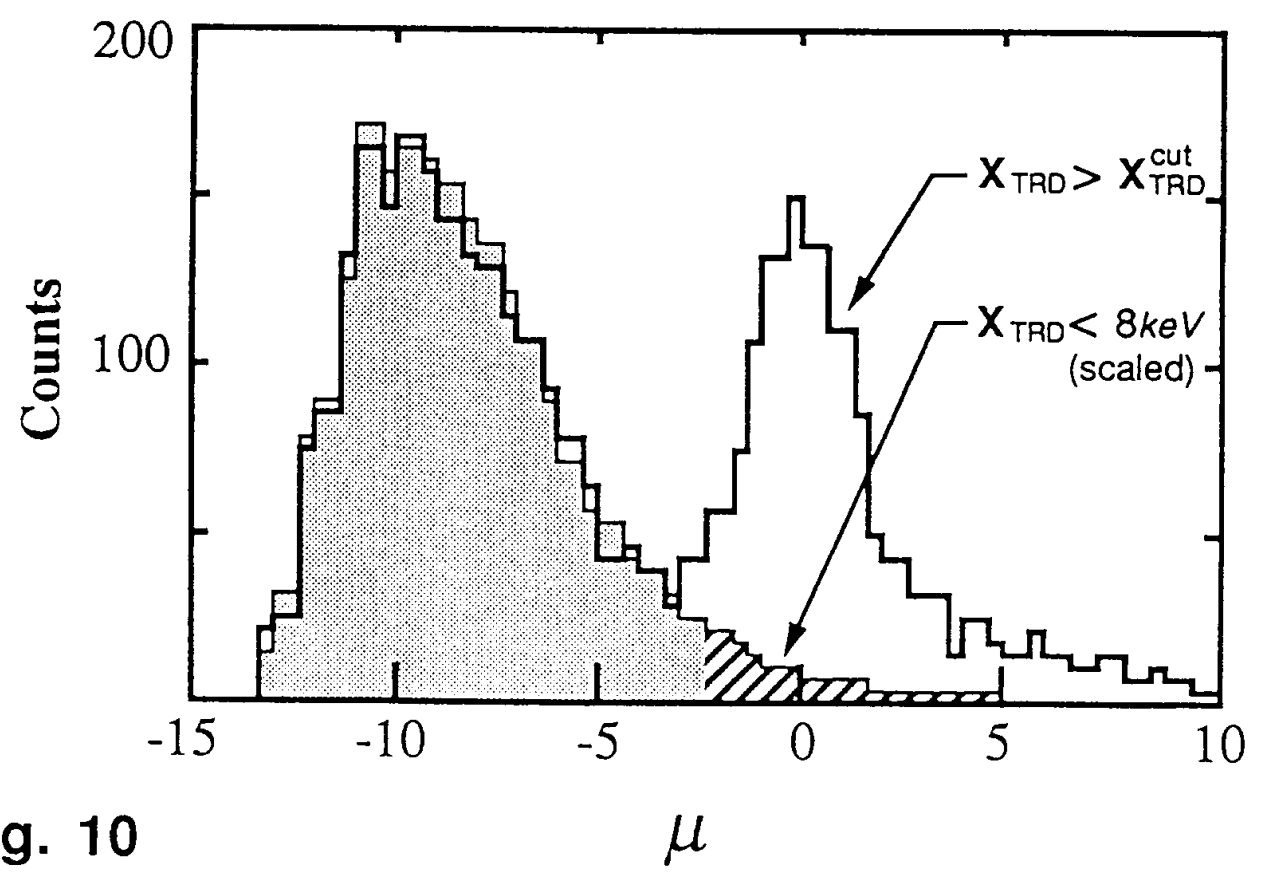




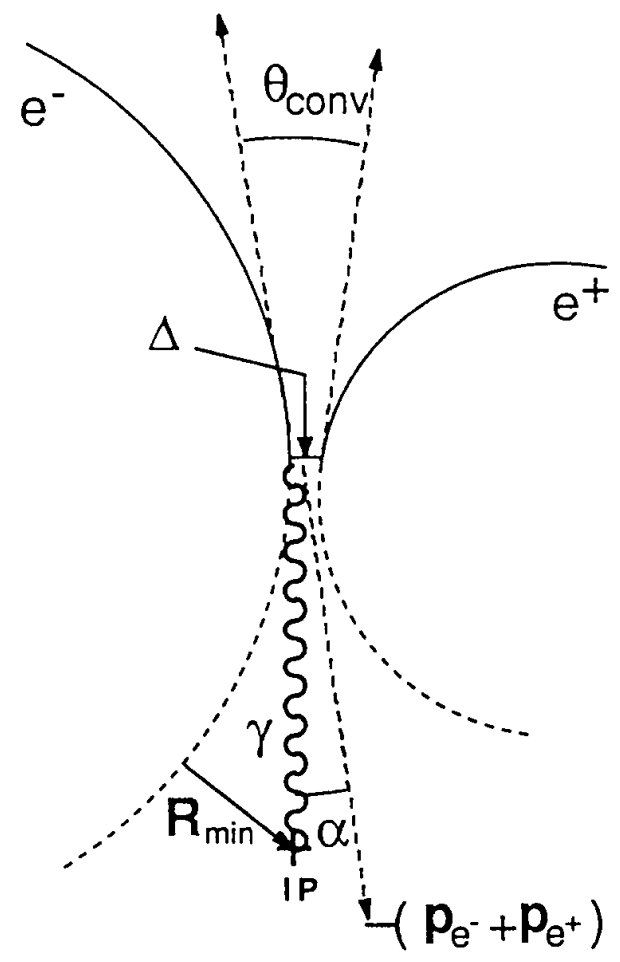

Fig. 11

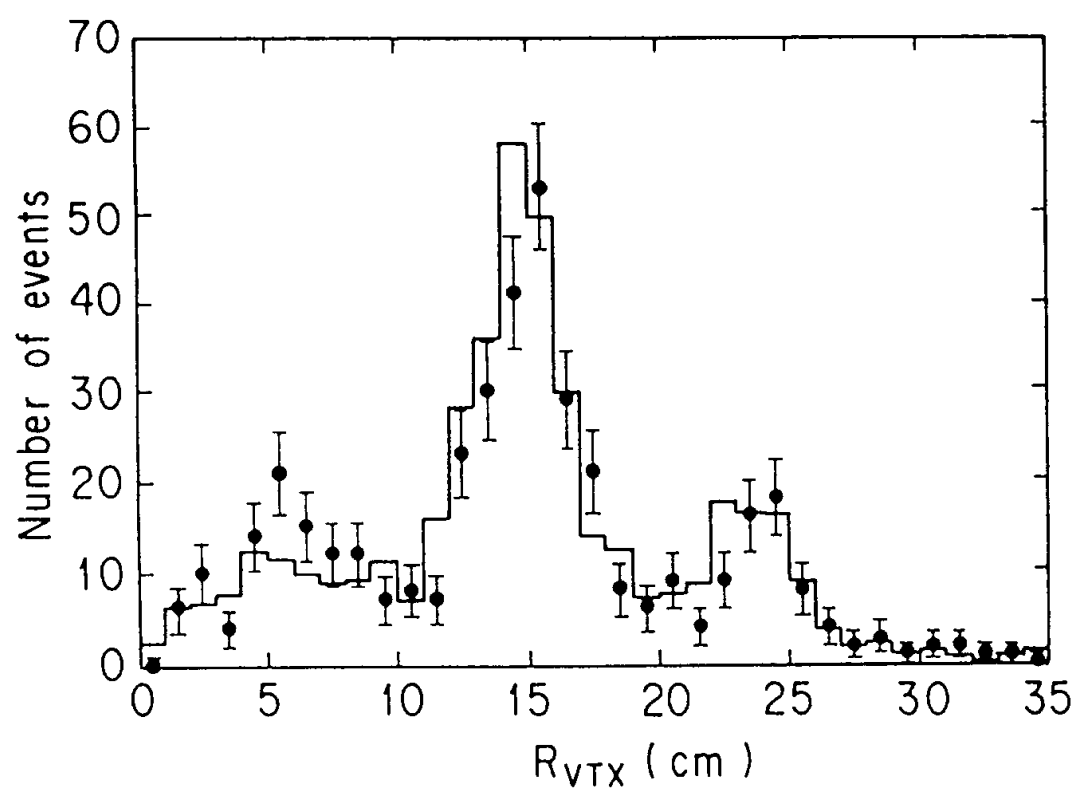

Fig. 12 
